\title{
Resection of Retro-Hepatic Vena Cava (RHVC) En-bloc with Caudate Lobe without Vascular Exclusion for a Low Grade Leiomyosarcoma of Inferior Vena Cava
}

\author{
Michele Altomare, $\mathrm{MD}^{1,2}$ (ㅁ) , Carlo Sposito, $\mathrm{MD}^{1,2}$ (D) , Enrico Regalia, $\mathrm{MD}^{2}$, Jorgelina Coppa, $\mathrm{MD}^{2}$, \\ Maria Flores, $\mathrm{MD}^{2}$, Elena Manzo, $\mathrm{MD}^{1,2}$, Michele Droz Dit Busset, $\mathrm{MD}^{2}$, and Vincenzo Mazzaferro, $\mathrm{MD}, \mathrm{PhD}^{1,2}$ \\ ${ }^{1}$ HPB Surgery and Liver Transplant Unit, IRCCS National Cancer Institute, University of Milan, Milan, Italy; ${ }^{2} \mathrm{HPB}$ \\ Surgery and Liver Transplant Unit, IRCCS National Cancer Institute, Milan, Italy
}

\begin{abstract}
Background. Leiomyosarcomas (LMS) of the inferior vena cava (IVC) originate in the retrohepatic (RHVC) portion in $15 \%$ of cases. ${ }^{1}$ Due to complex anatomy and need to preserve venous outflow from the infra-diaphragmatic viscera, the operation may require total vascular exclusion, veno-venous bypass and hypothermic liver resections. ${ }^{2,3}$ In this video, virtual planning of the operation allowed a parenchymasparing radical resection in a patient with limited liver reserve. Methods. A 12-cm LMS of RHVC invading the entire segment 1 (i.e., Spiegel's lobe, paracaval portion, and caudate process) was diagnosed in a man with metabolic steato-hepatitis (BMI: 34). He had no response to previous chemotherapy. Major hepatectomy was excluded considering the high risk of postoperative liver failure. 3D-reconstruction of regional anatomy allowed planning of a parenchymalsparing, en bloc resection of tumor, RHVC, and caudate lobe while avoiding hilar and suprahepatic venous clamping.

Results. The operation strategy relied on the en bloc separation of caudate lobe, RHVC, and tumor from the hepatic veins confluence and the posterior segments after complete mobilization of the liver. Vessel loop-assisted
\end{abstract}

Electronic supplementary material The online version of this article (https://doi.org/10.1245/s10434-020-09428-z) contains a video presenting the operation that can be seen with free access.

(C) The Author(s) 2021

First Received: 17 August 2020

Accepted: 6 November 2020;

Published Online: 22 January 2021

V. Mazzaferro, MD, PhD

e-mail: Vincenzo.Mazzaferro@unimi.it;

Vincenzo.Mazzaferro@istitutotumori.mi.it hanging maneuver, encircling tumor, and RHVC with superimposed 3D-reconstructions guided the parenchymal transection, while preserving the middle hepatic vein outflow. RHVC was replaced with prosthetic material.

Conclusions. Complex resection of primary tumor of the IVC en bloc with caudate lobe and RHVC can be attempted in chronic liver diseases at-risk of postoperative failure. Preservations of transhepatic flow and liver function depends on tumor size and preservation of noninvaded hepatic-veins confluence. Preoperative virtual 3D reconstruction is crucial in surgical planning.

Keywords Augmented reality .

3D virtual reconstruction - Transplant surgery .

Sarcoma surgery $\cdot$ Inferior vena cava

FUNDING Open access funding provided by Università degli Studi di Milano within the CRUI-CARE Agreement.

DISCLOSURE All authors declare not to have any commercial interest in the subject of study and that there is no source of any financial or material support.

OPEN ACCESS This article is licensed under a Creative Commons Attribution 4.0 International License, which permits use, sharing, adaptation, distribution and reproduction in any medium or format, as long as you give appropriate credit to the original author(s) and the source, provide a link to the Creative Commons licence, and indicate if changes were made. The images or other third party material in this article are included in the article's Creative Commons licence, unless indicated otherwise in a credit line to the material. If material is not included in the article's Creative Commons licence and your intended use is not permitted by statutory regulation or exceeds the permitted use, you will need to obtain permission directly from the copyright holder. To view a copy of this licence, visit http://creativecommons. org/licenses/by/4.0/. 


\section{REFERENCES}

1. Kulaylat MN, Karakousis CP, Doerr RJ, Karamanoukian HL, O'Brien J, Peer R. Leiomyosarcoma of the inferior vena cava: a clinicopathologic review and report of three cases. J Surg Oncol. 1997. https://doi.org/10.1002/(SICI)1096-9098(199707)65:3.

2. Ravaioli M, et al. Liver and vena cava en bloc resection for an invasive leiomyosarcoma causing Budd-Chiari Syndrome, under veno-venous bypass and liver hypothermic perfusion: liver hypothermic perfusion and veno-venous bypass for inferior vena cava leiomyosarcoma. Ann Surg Oncol. 2017. https://doi.org/10. 1245/s10434-016-5285-1.

3. Hardwigsen J, Balandraud P, Ananian P, et al. Leiomyosarcoma of the retrohepatic portion of the inferior vena cava: clinical presentation and surgical management in five patients. $J$ Am Coll Surg. 2005. https://doi.org/10.1016/j.jamcollsurg.2004.09.035.

Publisher's Note Springer Nature remains neutral with regard to jurisdictional claims in published maps and institutional affiliations. 